\section{THE FABRIC OF EARTH KINSHIP}

\author{
Michael J. Cohen, Ed.D. \\ National Audubon Society \\ Sharon, Connecticut
}

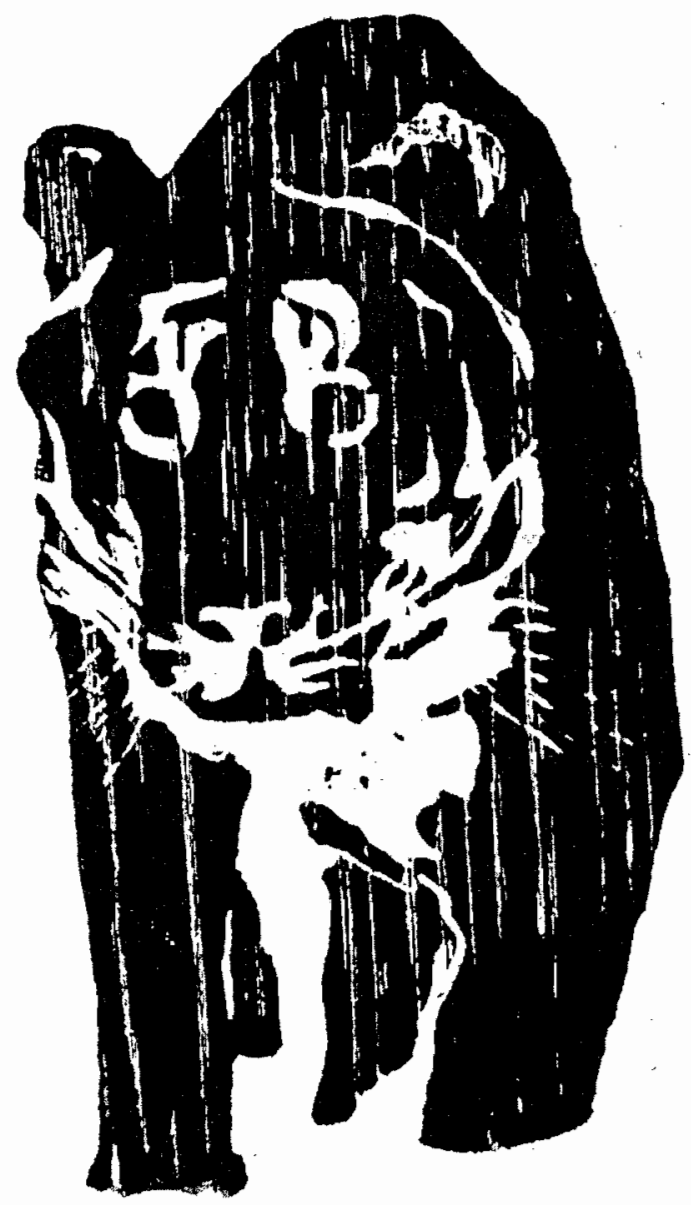

COPYAIGHT BEV PARISH 1977

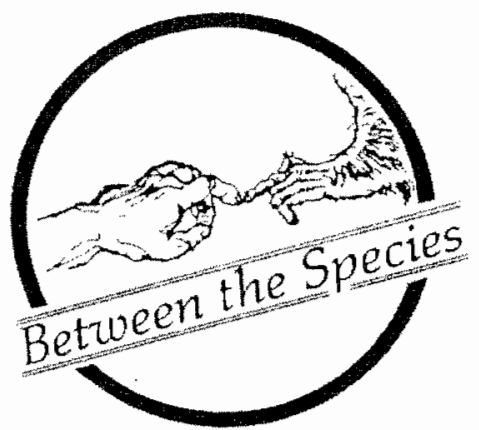

Few among us would try to stop a maniac like Jack the Ripper by having him read a book of ethics, for we realize that disturbed emotions, not unethical thoughts produced the insane murders he committed. So why do we so strongly believe in preaching sound ethical and ecological principles to mainstream society? Our insane society makes Jack the Ripper seem like an amateur.

Outrageously, mainstream's maniacal actions and attitudes needlessly kill, maim and hurt millions of animals, people and other life forms daily. For us animal rights people to espouse rational ecology and ethics and expect these to change our central way of life, should make us question how much mainstream society has affected our own mentality.

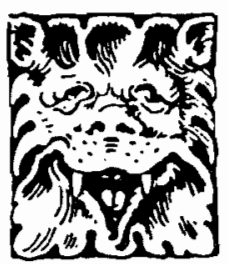


We must recognize that, more than ethics, facts and figures, America needs intense emotional understanding, treatment and controls if we're going to make interspecies peace, or make it into the $21 \mathrm{st}$ century for that matter.

Modern society is insane because it attacks Nature and therefore a vital part of itself. Nature within and around us is a seamless continuum built from affinity relationships that exist in and between all entities. Over the millennium, these affinities have grown and evolved Earth, our embodying and enveloping global life community.

Surviving while knowingly
destroying one's life support
system is an obvious form
of madness as evidenced by
the deteriorating state of
the Earth and most of its
people.

We experience some of Earth's life-giving affinities as sensations and feelings such as hunger, thirst, gravity and community, and although other signals from Nature like waves, particles and hormones usually escape our perception, our life affinities exist on all levels. They are the essence of our kinship with Earth and each other.

As our common culture strives to survive by changing nature into artifacts, it disrupts our natural affinity bonds within and without causing stress and destruction. Normally, as children, mainstream society rips us from our inborn affinities with Earth and subtly welds our severed, raw feelings to our culture's often misguided attitudes, technologies and built environment. This programs us to demean, fear and conquer all kinds of natural communities including those people who appear closer to nature such as women, blacks, children, indigenous persons and most minority groups. Such madness is mainstream's nature and we must address it if Jack is to stop ripping.
We hurt the natural world and each other when we blame special groups or individuals for causing our problems. The cause of our problems is our insane mainstream upbringing, not each other, for our upbringing has mistreated, conquered, and raped the Nature in each of us along with the natural world. That's the problem.

Modern insanity persists so long as we don't eliminate its source. We are seldom taught what many Anthropologists have long known: when humanity migrated from the tropics, our ancestors, during stressful times remembered the life supportive, womblike tropics of their origins and learned to survive anywhere by changing their immediate environment into places that artificially simulated the tropics. In this survival process memory signals from their consciousness superseded people's immediate signals from Nature. Consciousness became the dominant factor for these people's survival and in time people learned to value their mentality rather than the vital community of the natural world.

Falsely, people's consciousness became conscious of itself as the essential factor for survival, while assigning the self-organizing, life-perpetuating, regenerative signals and substances from the natural world to the subservient realm of raw materials and resources. Our established symbolism and technologies resist change because we subconsciously recognize them as means for survival.

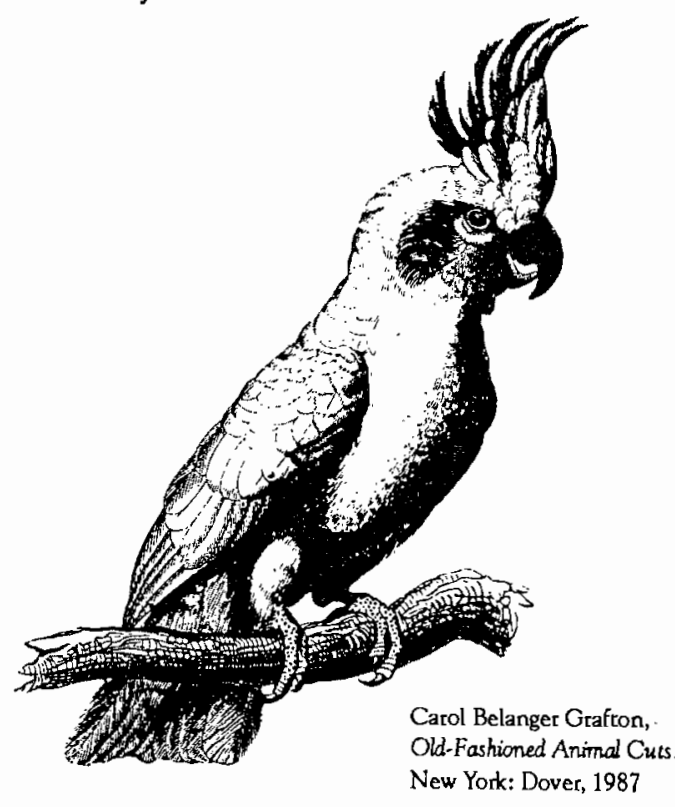


Today, our subconscious tropical values still combine with our nature-detached technologic prowess, demeaning nature while creating wilderness-isolated indoor environments of houses, schools, offices, destruction and stress. Here we spend over $95 \%$ of our time and imprint the next generation to more powerfully and dependently do the same.

Unlike the consciousness of indigenous people whose experiences taught them to sentiently relate to and revere Earth's ways and language, we still applaud ideas, powers, and acts that change the natural world into tropiclike artifacts even though they produce toxins and pollutants. But surviving while knowingly destroying one's life support system is an obvious form of madness as evidenced by the deteriorating state of the Earth and most of its people.

Isolated from Nature's normal control signals, our runaway "tropicmaking" desires - to our cost fuel, stress and blackmail our economics, education, relationships, armies and lifestyles. To adequately deal with our uncontrolled tropicmaking desires we must address their source in our emotions, not in our intellect alone.

Modern insanity stops when, with strong community support, we risk liberating our natural survival feelings from their hurtful bonding to our culture's destructive ways. We can then let that support and hurt motivate us to re-attach these feelings to the vital integrity of the natural world within and without. For survival, our feelings for life must become a love for Earth and environmentally and socially responsible living, not just a love to shop or improve Nature. To attain animal liberation we need feeling liberation.

Our troubles stem from not recognizing that Nature speaks to us through affinity sensations and feelings which we ignorantly demean as subjective, immature, irrational or inconsequential. To achieve harmony we must validate our feelings and relate sentiently to the natural community because it is illiterate. Survival for any species is neither a concept or technology, it is an emotion.

We may evoke peace by ceasing to psychologically imprint on money, power, conquest and separation from Nature. We culturally gain Nature's harmony by wisely communing with Nature within and without for this creates Nature sensitive relationships at all levels.

The world has never before dealt with the human impacts it faces today; newly created cultural solutions are necessary for sanity and survival. To this end, my book How Nature Works: Regenerating Kinship with Planet Earth, describes many regenerative forms of Earth kinship education. By equivocating Nature and feelings, they reverse the madness of America the Ripper.

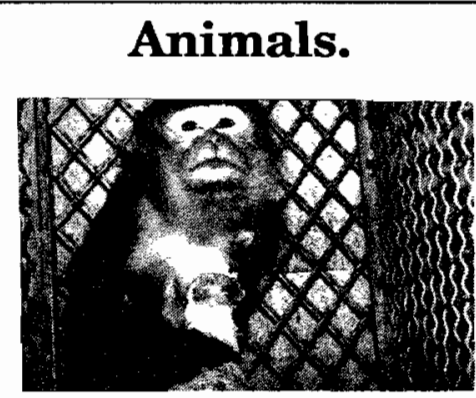

Do they matter?

The animal rights movement is as diverse as the animals it seeks to protect ... and only one publication, The ANIMALS' AGENDA, gives you comprehensive coverage of its successes, its problems, its people, and its organizations.

10 issues per year -65 pages and growing!!

YES. Send me The ANIMALS' AGENDA.
$\square 1$ yr.\$18.00 $\square$ 2 yrs. \$33.50
$\square$ 3 yrs. $\$ 45.00$
$\square$ Payment enclosed
$\square$ Bill me

Name:

Street:

City:

State: Zip Code:

The ANIMALS'AGENDA Subscriptions P.O. Box 6809

Syracuse, New York 13217 